\title{
Implementation of the WHO consolidated guideline on self-care interventions to strengthen sexual and reproductive health in the Eastern Mediterranean Region ${ }^{1}$
}

Citation: Implementation of the WHO consolidated guideline on self-care interventions to strengthen sexual and reproductive health in the Eastern Mediterranean Region. East Mediterr Health J. 2021;27(2):211-212 https://doi.org/10.26719/2021.27.2.211

Copyright (c) World Health Organization (WHO) 2021. Open Access. Some rights reserved. This work is available under the CC BY-NC-SA 3.0 IGO license (https://creativecommons.org/licenses/by-nc-sa/3.0/igo).

\section{Introduction}

The WHO Regional Office for the Eastern Mediterranean, Cairo Egypt, in collaboration with WHO headquarters, Geneva Switzerland, held a virtual meeting on 30 April 2020 to plan the rapid dissemination and implementation of the WHO consolidated guideline on selfcare interventions for sexual and reproductive health in the WHO Eastern Mediterranean Region (1). The purpose was to build national capacity in the planning and implementation of self-care interventions to respond to sexual and reproductive health needs during and after the COVID-19 pandemic. The meeting was attended by 35 participants from Jordan, Lebanon Morocco and Pakistan, including policy-makers, programme managers, nongovernmental organizations and representatives from the International Pharmaceutical Federation, Pan African Organization Against AIDS (OPALS), United Nations Population Fund (UNFPA), United Nations High Commissioner for Refugees and United Nations Relief and Works Agency for Palestine Refugees in the Near East (UNRWA).

The objectives of the meeting were to:

- share the key messages and recommendations of the 2019 WHO consolidated guideline on self-care interventions for health: sexual and reproductive health and rights (2) and on the need for rapid implementation to respond to COVID-19;

- discuss approaches and tools to influence timely policy and regulatory change to support the rapid introduction and scale-up of self-care interventions for sexual and reproductive health at country level; and

- support orientation activities to improve access and uptake of selfcare interventions, products and information through empowering individuals and communities.

\section{Summary of discussions}

Self-care interventions for sexual and reproductive health are vital to the continuity of reproductive and maternal health services, during and after the COVID-19 pandemic, to ensure that people have access to services, information and products and to reduce disparities. Self-care offers an opportunity for people to improve their ability to manage, control and contribute to their well-being. It is also a huge opportunity to reduce the burden on the health-care system.

Countries were requested to implement the five recommended self-care interventions (2). These interventions needed to be adapted to the local context, including health system capacity, availability of commodities and resources, and level of political support. The implementation of self-care interventions largely depends on advocacy, planning and working with local partners, utilizing the available resources and prioritizing vulnerable populations.

\section{Recommendations}

\section{To WHO}

- Maintaining technical support to Member States for implementation of self-care interventions for sexual and reproductive health during and after the COVID-19 pandemic; and

- sharing with Member States up-to-date guidance and recommendations to support national efforts to adopt self-care interventions for improving sexual and reproductive health during and after the COVID-19 pandemic.

\section{To Member States}

- Advocating for implementing self-care interventions using successful examples from other countries in the Region, taking into consideration the five selfcare interventions recommended by WHO and work with partners and stakeholders to plan self-care interventions;

- strengthening sexual and reproductive health services during the COVID-19 pandemic through the adoption of self-care interventions;

- leveraging digital health technologies and platforms to inform people about services and delivering

\footnotetext{
This summary is extracted from the Summary report on a WHO online consultation in response to the COVID-19 pandemic on the planning for rapid dissemination and implementation of the WHO consolidated guideline on self-care interventions to strengthen sexual and reproductive health in the Eastern Mediterranean Region, virtual meeting, 30 April 2020 (https://applications.emro.who.int/docs/WHOEMWRH11oE-eng.pdf?ua=1).

2 1) Self-administration of DMPA-SC; 2 ) over-the-counter availability of oral contraceptive pills; 3) human papilloma virus (HPV) self-sampling; 4) fertility regulation home-based ovulation prediction; 5) self-testing for sexually transmitted infections.
} 
messages to the community on self-care using information, education and communication materials, infographics, media and social media; and
- documenting successful practices for sexual and reproductive health self-care interventions to showcase country efforts in a regional strategy on self-care.

\section{References}

1. World Health Organization Regional Office for the Eastern Mediterranean (WHO/EMRO). WHO online consultation in response to the COVID-19 pandemic on the planning for rapid dissemination and implementation of the WHO consolidated guideline on self-care interventions to strengthen sexual and reproductive health in the Eastern Mediterranean Region, virtual meeting, 30 April 2020 (https://applications.emro.who.int/docs/WHOEMWRH11oE-eng.pdf?ua=1).

2. World Health Organization. WHO consolidated guideline on self-care interventions for health: sexual and reproductive health and rights. Geneva: World Health Organization; 2019 (https://www.who.int/reproductivehealth/publications/self-care-interventions/en/). 